\title{
Utilization of free lysine by growing pigs
}

\author{
BY E. S. BATTERHAM AND R. D. MURISON \\ NSW Department of Agriculture, Agricultural Research Centre, Wollongbar, New South \\ Wales 2480, Australia
}

(Received 7 October $1980-$ Accepted 14 January 1981)

1. The results of nine estimates of the efficiency of utilization of supplements of free lysine by growing pigs fed once daily and reported by Batterham (1974) and Batterham \& O'Neill (1978) were re-analysed using carcass rather than live-weight values as the criteria of response.

2. The efficiency of utilization of free lysine with once daily feeding relative to frequent feeding was 0.53 using carcass gain as the criterion of response $(P<0.001)$, and 0.56 using food conversion efficiency on a carcass basis $(P<0.001)$. These estimates were lower than estimates of 0.67 using live-weight gain $(P<0.01)$ and 0.77 using food conversion ratio on a live-weight basis $(P<0.05)$.

3. The results indicate that current estimates of the lysine requirements of pigs that are based on responses to supplements of free lysine under once daily feeding regimens may be $10-30 \%$ over-estimated, as a result of incomplete utilization of the free lysine.

Batterham (1974) reported that the efficiency of utilization of free lysine by growing pigs fed once daily was only 0.43 of that of pigs given the same ration in six equal portions at three-hourly intervals. It was suggested that the lower response with once daily feeding was due to differential rates of absorption of free lysine and the protein-bound amino acids. By feeding frequently, a more balanced supply of amino acids would arrive at the sites of absorption and metabolis:n, thereby resulting in more efficient utilization. An additional eight estimates of free lysine utilization were reported by Batterham \& O'Neill (1978), conducted over a range of basal diets and comparing wet and dry feeding systems. They reported considerable variation in their estimates of lysine utilization, from $0 \cdot 31-1 \cdot 01$, with an over-all mean of 0.67 . No relationship between type of diet or feeding system with lysine utilization was established. They concluded that the variation in estimates may have been due to 'within experiment' pig variation, as the estimates were sensitive to small changes in pig performance on any one treatment.

The estimates of Batterham (1974) and Batterham \& O'Neill (1978) were based on traditional measurements of live-weight gain and food conversion ratio as the indices of pig response. However, Batterham et al. (1979) reported that with slope-ratio assays with pigs, potency estimates based on carcass values appeared more reliable than those based on live-weight values, as the potency estimates were sensitive to small changes in gut contents. In the results of Batterham (1974) and Batterham \& O'Neill (1978) dressing percentage was affected by a number of factors including interactions between frequency of feeding and lysine response. Accordingly the results have been analysed on a carcass basis to remove any effect variation in gut contents may have had on the original estimates of free lysine utilization.

\section{EXPERIMENTAL}

Lysine utilization was detismined by Batterham (1974) and Batterham \& O'Neill (1978) by comparing the responst: of pigs to supplements of $2 \mathrm{~g} \mathrm{~L}$-lysine (as L-lysine monohydrochloride, anhydrous)/ $\mathrm{kg}$ diet under once daily and frequent feeding regimens (six feeds/d at intervals of $3 \mathrm{~h}$ ). The level of $2 \mathrm{~g} \mathrm{~L}$-lysine/ $\mathrm{kg}$ was chosen to observe the response under the two feeding regimens in conditions in which the full response to the added free lysine 
should be obtained. Batterham (1974) included an additional treatment of $4 \mathrm{~g} \mathrm{~L}-\mathrm{lysine} / \mathrm{kg}$ diet to show that the diets supplemented with $2 \mathrm{~g} \mathrm{~L}$-lysine $/ \mathrm{kg}$ were in fact still lysine deficient. This treatment was restricted to the frequent feeding regimen only by Batterham \& O'Neill (1978) for five experiments, because it was anticipated that the responses to $4 \mathrm{~g} \mathrm{~L}$-lysine/ $\mathrm{kg}$ with frequent feeding would be equal or superior to that with once daily feeding. In the sixth experiment of Batterham \& O'Neill (1978) diets were supplemented with $0,1,2,3$ and $4 \mathrm{~g} \mathrm{~L}$-lysine $/ \mathrm{kg}$ to allow a response curve to lysine supplementation to be defined for both feeding regimens.

Carcass gain $/ \mathrm{d}$ ( $\mathrm{kg}$ cold carcass weight $-(\mathrm{kg}$ initial live weight $\times 0.74) \div$ period $(\mathrm{d})$ on experiment) and food conversion efficiency (FCE) on a carcass basis ( $\mathrm{kg}$ cold carcass weight $-(\mathrm{kg}$ initial live weight $\times 0.74) \div \mathrm{kg}$ food intake) were calculated using a factor of 0.74 for estimated initial dressing proportion at the commencement of the experiments. The factor of 0.74 was determined with four piglets slaughtered at $20 \mathrm{~kg}$ live weight after they had been trained in a similar manner to those used previously.

The experiments were analysed individually as well as a combined analysis on the nine estimates from Batterham (1974) and Batterham \& O'Neill (1978). For the combined analysis, wet $v$. dry feeding was confounded with experiments, except in Expts 5 and 6, where direct comparisons of wet and dry feeding were made. Accordingly only the results for Expts 5 and 6 were used for the wet $v$. dry feeding comparison in the combined analysis. The results for dressing proportion (cold carcass weight as a proportion of live weight) for the individual experiments are also presented as these results were not presented previously.

\section{RESULTS}

For the combined analysis, the mean response to $2 \mathrm{~g} \mathrm{~L}$-lysine $/ \mathrm{kg}$ diet with once daily feeding was only 0.53 of that with frequent feeding, using carcass gain as the criterion of response $(P<0.001$; Table 1$)$ and 0.56 using FCE on a carcass basis $(P<0.001$; Table 2$)$. This compares with responses of 0.67 using live-weight gain $(P<0.01$; Table 1$)$ and 0.77 using food conversion ratio $(P<0.05$; Table 2$)$.

The individual estimates for lysine utilization were lower using carcass gain $(0 \cdot 19-0.89)$ and FCE on a carcass basis $(0.28-0.83)$ compared to live-weight gain $(0.31-1.01)$ and food conversion ratio $(0 \cdot 28-1 \cdot 27)$. The statistical significances of the interaction between frequency of feeding and response to $2 \mathrm{~g} \mathrm{~L}$-lysine/ $\mathrm{kg}$ diet were greater in Expts 1, 6 for carcass gain and Expts 1, 6, 7 for FCE on a carcass basis.

Dressing proportion was affected by frequency of feeding in Expts $3(P<0.01), 5$ $(P<0.05), 6(P<0.001), 7(P<0.001)$, lysine response (Expt $7, P<0.05)$, wet $v$. dry feeding (Expt 6, $P<0.001$ ) and interaction between frequency of feeding and lysine response (Expts 1, 2, $P<0.05$ ) (Table 3 ).

The response of $4 \mathrm{~g} v .2 \mathrm{~g} \mathrm{~L}$-lysine $/ \mathrm{kg}$ diet with frequent feeding was significant for all experiments except Expts 2, 4, 5 for carcass gain and Expts 4, 5 for FCE on a carcass basis. In Expt 7, only the linear component of the lysine response was significant $(P<0.001)$. It was the only component of the lysine response to vary significantly between the number of feeds/d $(P<0.01$ for carcass gain/d; $P<0.001$ for FCE on a carcass basis).

\section{DISCUSSION}

The estimates of free lysine utilization based on carcass values are more applicable than estimates based on live-weight values as the effects of variation in gut contents have been removed and the interactions between frequency of feeding and lysine response are statistically more significant. The over-all estimates of 0.53 for carcass gain and 0.56 for FCE on a carcass basis are considerably lower than estimates of 0.67 and 0.77 for gain and food conversion ratio on a live-weight basis. Variation in individual estimates was also 


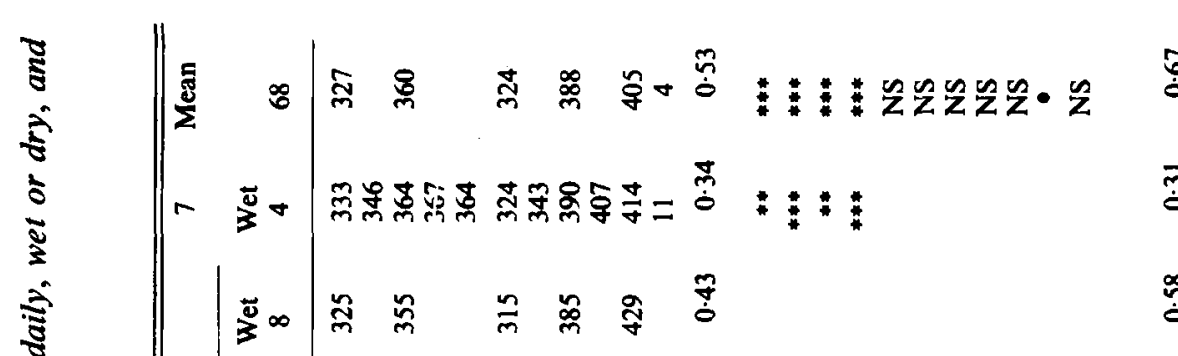

蛋

.

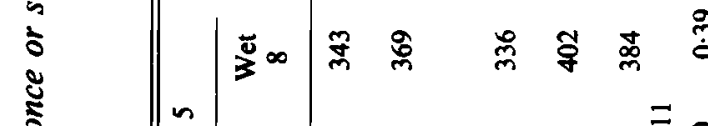

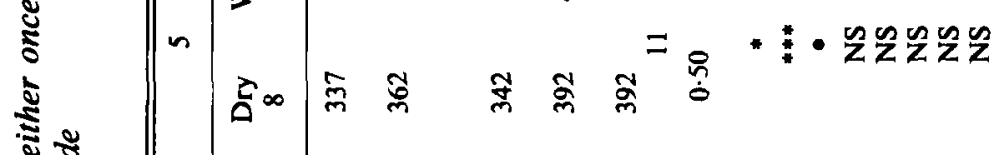

ป⿱艹

के

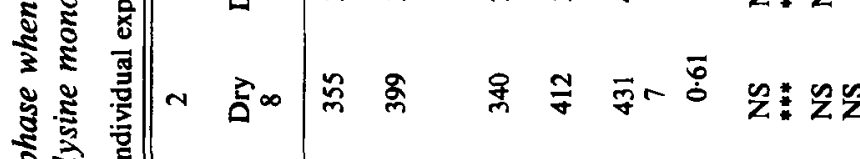

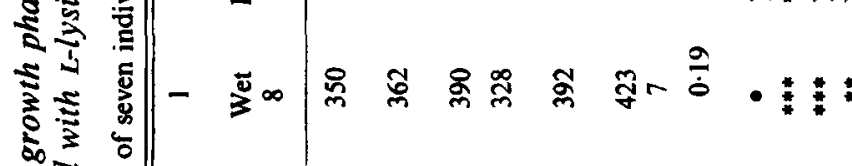

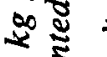

$\hat{\mathrm{I}}$

는

క

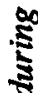

s。

8

ธ่

8

퐁

$\infty$

岁

ป

뭉 


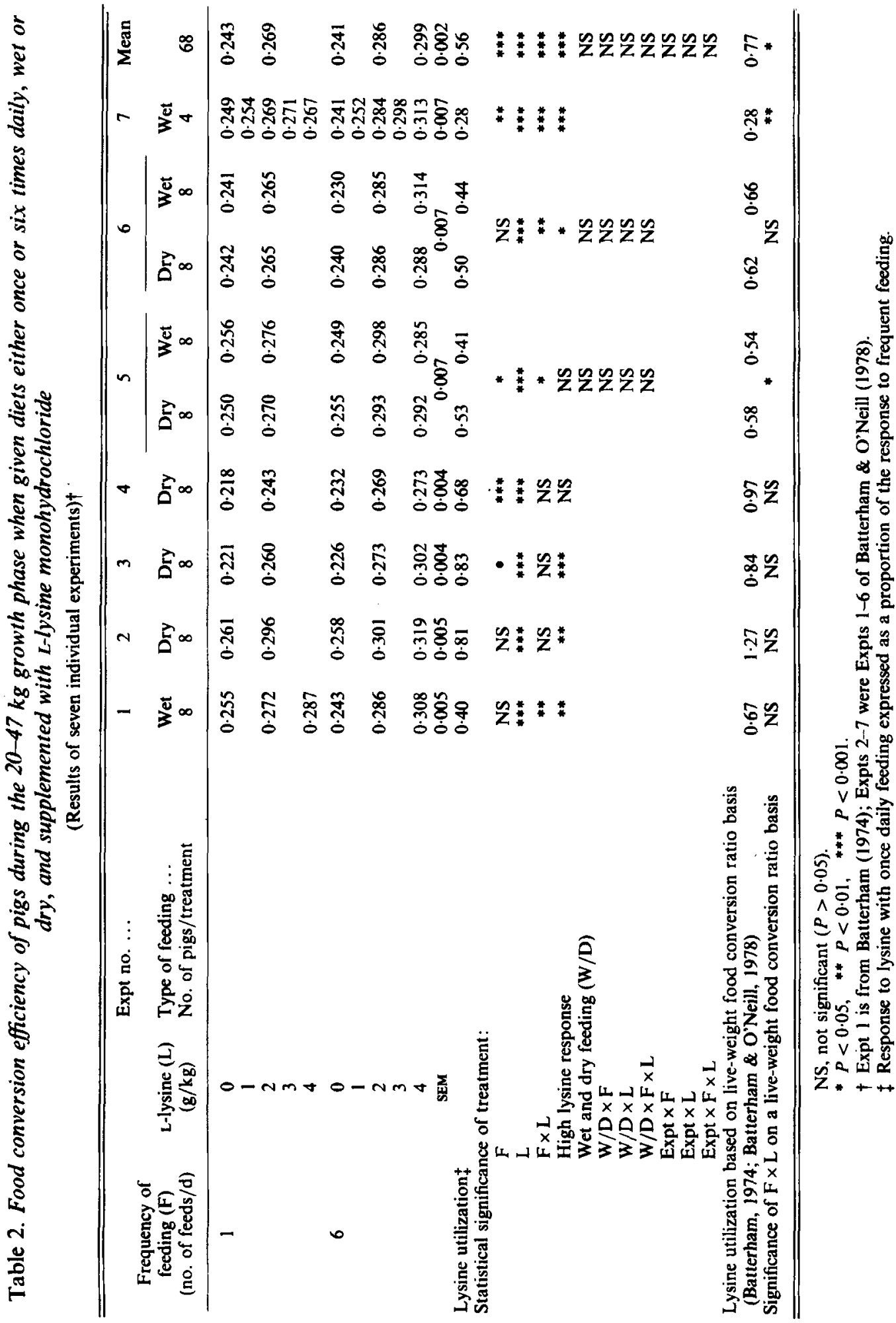




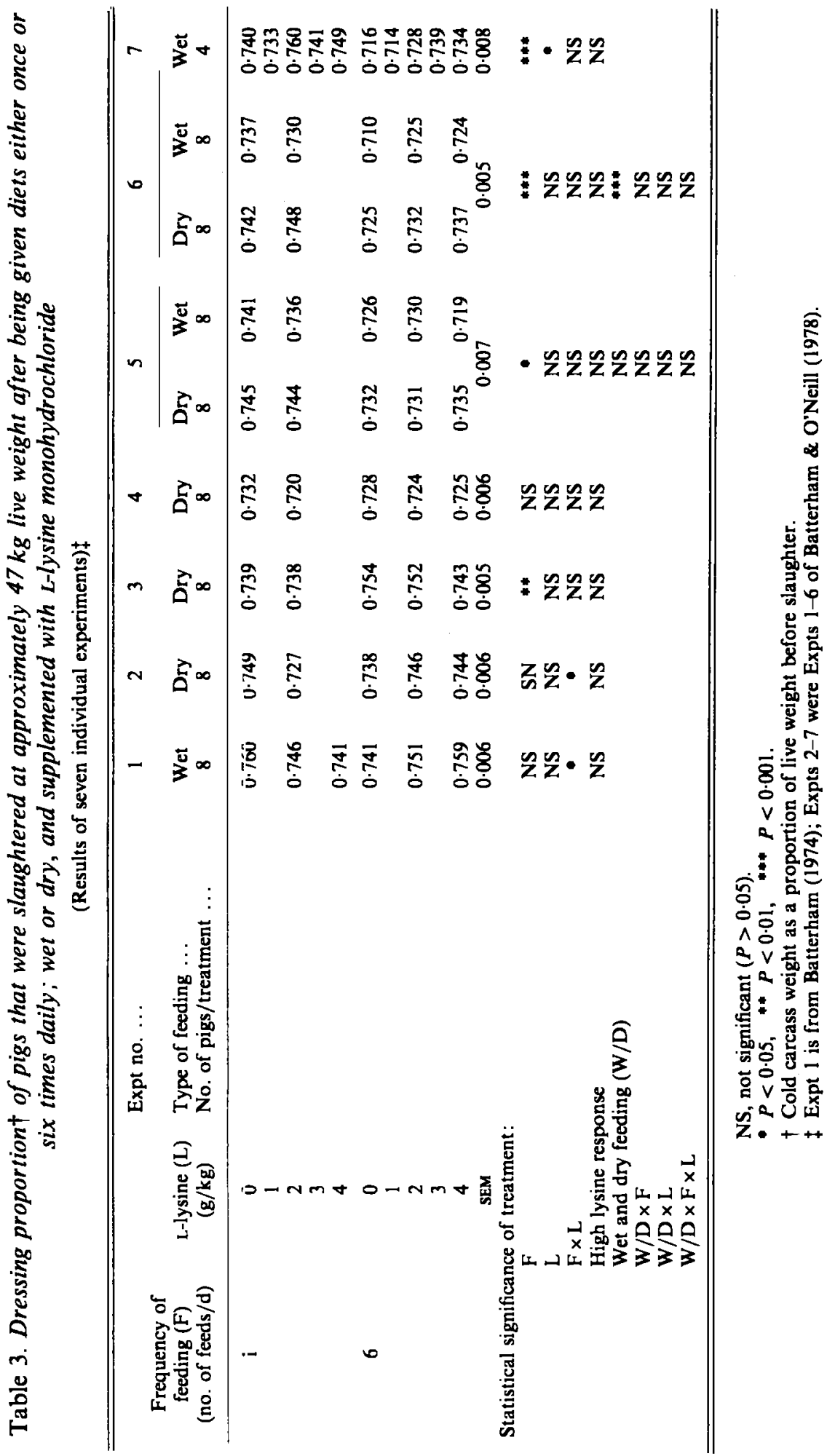


reduced, particularly with the estimates based on FCE on a carcass basis. The treatment effects on dressing proportion were inconsistent between experiments (Table 3 ). The effect of removing gut contents on the estimates of lysine utilization was not anticipated as the experiments were balanced for the different treatment effects. Live-weight values were normally used as the index for assessing pig response. It is apparent from the current studies and the results with slope-ratio assays (Batterham et al. 1979) that carcass values are more applicable if the responses are sensitive to small changes in pig performance within any one treatment.

The approximate 0.50 wastage of free lysine with once daily feeding means that it is essential when determining the pig's response to supplements of free lysine to ensure that the lysine is given under conditions that ensure its full utilization. This may not have been achieved in many of the experiments that have been used to derive the current estimates of the pig's requirement for lysine. Up until now it has been assumed that supplements of free amino acids are fully utilized under limited feeding systems. As a consequence, current estimates for lysine requirements of growing pigs and sows could be $10-30 \%$ over-estimated (Batterham, 1980). A similar situation may also apply with current estimates for the other essential amino acids, as it is most likely that differential rates of absorption between the free and protein-bound forms occurs (Pion et al. 1972; Rolls et al. 1972; Rerat et al. 1976). Until estimates of the efficiency of utilization of the other essential amino acids under limited feeding regimens are reported it seems desirable to assume that they are utilized in a similar manner to free lysine, i.e. approximately 0.50 with once daily feeding.

Batterham, E. S. (1974). Br. J. Nutr. 31, 237.

\section{REFEREN CES}

Batterham, E. S. (1980). In Recent Advances in Animal Nutrition - 1979, p. 11 [W. Haresign \& D. Lewis, editors]. London: Butterworths.

Batterham, E. S., Murison, R. D. \& Lewis, C. E. (1979). Br. J. Nutr. 41, 383.

Batterham, E. S. \& O’Neill, G. H. (1978). Br. J. Nutr. 39, 265.

Pion, R., Prugnaud, J. \& Rerat, A. (1972). Nutr. Rep. int. 6, 331.

Rerat, A., Corring, T. \& Laplace, J. P. (1976). In Protein Metabolism and Nutrition, p. 97 [D. J. A. Cole, K. N. Boorman, P. J. Buttery, D. Lewis, R. J. Neale and H. Swan, editors]. London: Butterworths.

Rolls, B. A., Porter, J. W. G. \& Westgarth, D. R. (1972). Br. J. Nutr. 28, 283. 